\title{
Compensatory growth mechanisms in lettuce plants after partial defoliation
}

\author{
Fánor Casierra-Posada ${ }^{1 *}$, Valentina Zapata-Casierra ${ }^{2}$, and Stefannie Tatiana Baker-Rodríguez ${ }^{2}$ \\ ${ }^{1}$ Universidad Pedagógica y Tecnológica de Colombia, Facultad de Ciencias Agropecuarias, Avenida Central del Norte 39-115, Tunja, \\ Colombia. "Corresponding author (fanor.casierra@uptc.edu.co). \\ ${ }^{2}$ Universidad Pedagógica y Tecnológica de Colombia, Facultad de Ciencias, Avenida Central del Norte 39-115, Tunja, Colombia.
}

Received: 27 October 2020; Accepted: 24 December 2020; doi:10.4067/S0718-58392021000200246

\begin{abstract}
Leaf area loss is a frequent problem in crops, and it can be caused by biotic or abiotic factors. Reduced leaf area can produce alterations in plants, affecting their metabolism, growth, and yield. The leaf area in lettuce plants (Lactuca sativa L.) is often affected by herbivores such as slugs. The effects of partial defoliation on the growth of lettuce plants were evaluated under greenhouse conditions in Tunja, Colombia. Some plants had half of their leaves removed, while others were left intact as a control. The variables normally used in the basic analysis of plant growth were evaluated. There was nonsignificant difference between the two treatments; however, lettuce plants showed a remarkable ability to reduce the negative effect caused by partial defoliation, and they managed to maintain a balance in the root to shoot ratio, leaf area ratio, specific leaf area, leaf weight ratio, DM partitioning, and harvestable DM. Partial defoliation decreased the absolute growth rate by $17.8 \%$ and the relative growth rate by $13.8 \%$. Additionally, the chlorophyll content index and the number of leaves increased by $16.0 \%$ and $15.4 \%$, respectively, in plants subjected to partial defoliation compared with the control plants. These results indicate the regeneration capacity of the plants after partial defoliation.
\end{abstract}

Key words: Biomass, chlorophyll, growth, herbivores, slugs.

\section{INTRODUCTION}

The direct measurement or indirect estimation of the leaf area is decisive for plant growth and development because the leaf is an essential plant structure that allows gas exchange and transformation of light energy into chemical energy useful for cell functions (Santos et al., 2018). However, the leaf area loss can be due to phytosanitary problems such as insects (herbivores) or phytopathogens, which can occur when pesticide use is decreased. Therefore, the growth of plants affected by some level of defoliation is largely dependent on the photoassimilates produced in the remaining plant leaf area. This, in turn, can be used to promote new shoot growth (Boogaard et al., 2001). According to Quentin et al. (2011), a 45\% reduction in the leaf area of Eucalyptus globulus can be tolerated; this is likely due to the increased photosynthetic rate and improved use of water and photoassimilates.

Partial defoliation has far-reaching effects on plant growth and development. Among these are the important changes in fruit quality of Vitis vinifera (common grape vine). These changes in the relationship between mean weight of the bunch and mean weight of the grape were shown to be higher in plants with reduced leaf area. Additionally, the value of all fruit quality parameters increased with partial defoliation, except for total titratable acidity, which was higher in intact plants (Peña-Olmos and Casierra-Posada, 2015). An increase in total soluble solids, $\mathrm{pH}$ value, and potential alcohol content of the wine from the partially defoliated $V$. vinifera plants were demonstrated. The total wine titratable acidity decreased when it came from partially defoliated plants (Peña-Olmos et al., 2013). In Fragaria spp. (strawberry) plants, partial defoliation induced a drastic reduction in the mean values of total soluble solids, the ratio between total soluble solids and acidity of the fruit juice, amount of harvested fruit, fruit weight and size, and finally, the value of leaf area/fruit yield 
ratio (Casierra-Posada et al., 2013). Regardless of whether the plants are arboreal or herbaceous, partial defoliation has a considerable effect on them. Paixao et al. (2019) found that defoliation caused by herbivores in Abies balsamea (balsam fir) and Picea mariana (black spruce) trees reduced annual radial growth and modified latewood cells. The density and quality of the wood in these plants are severely affected by defoliation; however, it was reported that it was possible to maintain a higher density of reproductive branches and optimize yield in Rubus idaeus (red raspberry) when increasing light exposure and specific hydraulic conductance of leaves by partially removing the leaf area (Qiu et al., 2016).

The objective of the present study was to evaluate the effect of artificial leaf removal on the growth of lettuce (Lactuca sativa) plants. Some $50 \%$ of the leaves were removed, and lettuce was chosen because it is a common food for Deroceras reticulatum (slugs) (Córdoba and León, 2010). These slugs can cause leaf area losses of $29.8 \%$ in lettuce when there is no mollusk control (Santacruz et al., 2011).

\section{MATERIALS AND METHODS}

\section{Site characterization}

Experiments were conducted in the greenhouse of the Faculty of Agricultural Sciences at the Universidad Pedagógica y Tecnológica de Colombia (UPTC) in Tunja (5³3'10.62” N, 73²1'23.97” W; 2690 m a.s.1.), Colombia. During the $66 \mathrm{~d}$ experiment, mean temperature was $20.9{ }^{\circ} \mathrm{C}$, relative humidity was $72.3 \%$, and $896.3 \pm 356.9 \mu \mathrm{mol} \mathrm{m}^{-2} \mathrm{~s}^{-1}$ of light was recorded inside the greenhouse.

\section{Data collection and handling}

One hundred lettuce (Lactuca sativa L.) 'Coolguard MI' seedlings were used. The 8 wk-old plants were transplanted to pots with a $3 \mathrm{~kg}$ capacity filled with local soil (Andisol). One week after transplanting, plants were divided into two groups of 50. One group was used as a control and the other was subjected to partial defoliation. For partial defoliation, half of each leaf was removed lengthwise with care to not damage the midrib. This procedure was initially performed on all the leaves of the partial defoliation group and subsequently carried out weekly on newly emerged leaves. Additionally, leaf area and weight of the removed leaves were recorded each time. The 50 plants of the control group grew without any defoliation.

Fifty days after transplanting, the chlorophyll content index (CCI) was recorded with a chlorophyll meter (CCM-200, Opti-Sciences, Hudson, New Hampshire, USA). Sixty-six days after transplanting, plants were harvested and data were collected. Final leaf area was measured with a portable leaf area meter (Li-3000A, LI-COR, Lincoln, Nebraska, USA); the dry weight of stems, leaves, and roots was also determined, and the number of leaves per plant was counted. Based on this information, total dry weight per plant, DM partitioning, root to shoot ratio, leaf area ratio, specific leaf area, leaf weight ratio, harvestable DM, and absolute and relative growth rates were calculated according to the methodology developed by Hunt (1990).

\section{Experimental design and statistical analysis}

The 50 control and 50 partially defoliated plants were randomly placed in the greenhouse. A statistical analysis was performed with the SPSS version 24.0 application (IBM, Armonk, New York, USA). An ANOVA was performed by Tukey's honest significant difference (HSD) test $(\mathrm{P}<0.05)$.

\section{RESULTS}

The allometric coefficients, root to shoot ratio, leaf area ratio, specific leaf area, leaf weight ratio, harvestable DM, and DM partitioning in the different plant tissues showed nonsignificant differences between partially defoliated plants and control plants (Table 1). The CCI increased $16 \%$ in plants subjected to partial defoliation when compared with the control plants, exhibiting a significant difference $(\mathrm{P}<0.05)$ (Table 1).

The relative growth rate (RGR) and absolute growth rate (AGR) values as a result of defoliation at the end of the experiment (66 d after transplanting) decreased by $13.8 \%$ and $17.8 \%$, respectively, when compared with the control plants. These rates are significantly different $(\mathrm{P}<0.01)$, as shown in Table 1 . It was also found that partially defoliated plants had $15.4 \%$ more leaves than control plants with a significant difference $(\mathrm{P}<0.01)$ (Figure 1). 
Table 1. Simple allometric ratios in lettuce plants (Lactuca sativa) subjected to partial leaf removal $(\mathbf{n}=\mathbf{5 0})$.

\begin{tabular}{|c|c|c|c|c|c|}
\hline \multirow[b]{2}{*}{ Variable } & & \multicolumn{2}{|c|}{ Control } & \multicolumn{2}{|c|}{$\begin{array}{c}\text { Partial leaf removal } \\
(50 \%)\end{array}$} \\
\hline & & Mean & SE & Mean & SE \\
\hline \multirow[t]{3}{*}{ Dry matter partitioning, $\%$} & Leaves & $60.5 \mathrm{a}$ & 1.07 & $60.5 \mathrm{a}$ & 1.06 \\
\hline & Stems & $15.0 \mathrm{a}$ & 0.80 & $16.1 \mathrm{a}$ & 0.79 \\
\hline & Roots & $24.3 \mathrm{a}$ & 1.08 & $23.2 \mathrm{a}$ & 1.07 \\
\hline Root to shoot ratio & & $0.3 \mathrm{a}$ & 0.02 & $0.3 \mathrm{a}$ & 0.02 \\
\hline Leaf area ratio, $\mathrm{mm}^{2} \mathrm{mg}^{-1}$ & & $16.3 \mathrm{a}$ & 0.71 & $14.6 \mathrm{a}$ & 0.70 \\
\hline Specific leaf area, $\mathrm{mm}^{2} \mathrm{mg}^{-1}$ & & $27.3 \mathrm{a}$ & 0.71 & $24.5 \mathrm{a}$ & 0.70 \\
\hline Leaf weight ratio & & $0.6 \mathrm{a}$ & 0.01 & $0.6 \mathrm{a}$ & 0.01 \\
\hline Harvestable dry matter & & $0.7 \mathrm{a}$ & 0.01 & $0.7 \mathrm{a}$ & 0.01 \\
\hline Chlorophyll content index & & $11.1 \mathrm{~b}$ & 2.76 & $12.9 \mathrm{a}$ & 3.05 \\
\hline Absolute growth rate, $\mathrm{g} \mathrm{d}^{-1}$ & & $0.049 \mathrm{a}$ & 0.017 & $0.040 \mathrm{~b}$ & 0.010 \\
\hline Relative growth rate, $\mathrm{g} \mathrm{g}^{-1} \mathrm{~d}^{-1}$ & & $0.525 \mathrm{a}$ & 0.023 & $0.452 b$ & 0.022 \\
\hline
\end{tabular}

The same letters in a row indicate that there is nonsignificant difference according to Tukey's honest significant difference (HSD) test $(\mathrm{P}<0.05)$

The values are mean values, followed by their respective standard error (SE).

Figure 1. Number of leaves in lettuce plants (Lactuca sativa) subjected to partial leaf removal compared with control plants with no leaf removal at the end of the experiment $(n=50)$.

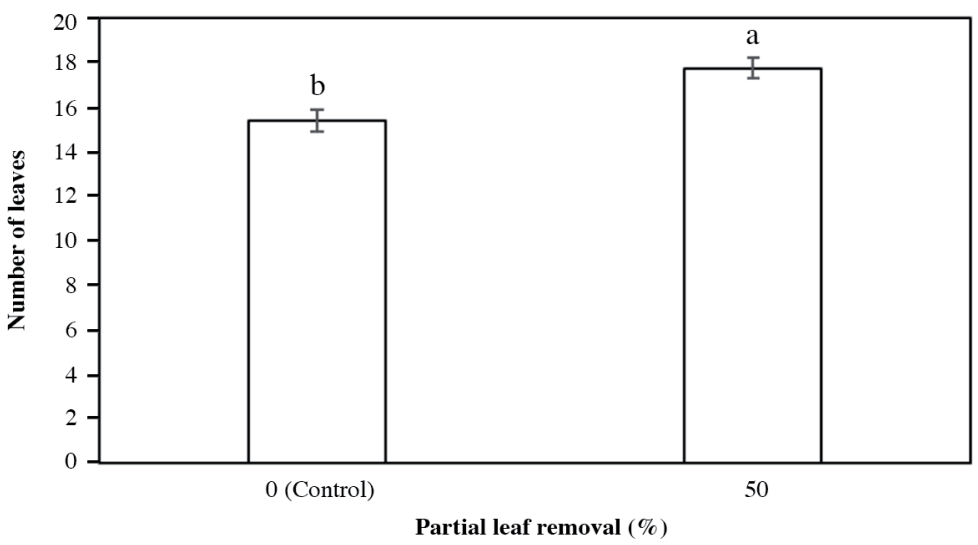

At the end of the study, total dry mass per plant decreased by $17.2 \%$ in plants subjected to partial defoliation compared with the control plants. This was a significant difference $(\mathrm{P}<0.05)$, whereas there was nonsignificant difference in the total dry mass produced during the experiment. This was evaluated by determining the sum of the dry mass at the end of the experiment and the dry mass removed from the plants subjected to defoliation (Figure 2).

Leaf area decreased by $26.6 \%$ in plants subjected to partial defoliation when compared with the control plants at the end of the study, and the difference was significant $(\mathrm{P}<0.01)$. However, nonsignificant difference was found when total leaf area was calculated throughout the study by adding leaf area at the end of the experiment with leaf area removed, (Figure 3).

Leaf dry weight at the end of the experiment showed a significant difference $(\mathrm{P}<0.05)$ in partially defoliated plants, which decreased by $17.3 \%$ compared with the control plants. The sum of the dry weight of the leaf area removed and leaf dry weight at the end of the experiment was not significantly different between treatments (Figure 4). Similarly, the amount of leaf dry mass compared with the total plant dry weight (DM partitioning) was not significantly different (Table 1). 
Figure 2. Dry matter production per plant at harvest (white bars) and the sum of dry weight at harvest plus dry weight of removed leaves (gray bars) in lettuce plants (Lactuca sativa) subjected to partial leaf removal $(\mathbf{n}=\mathbf{5 0})$.

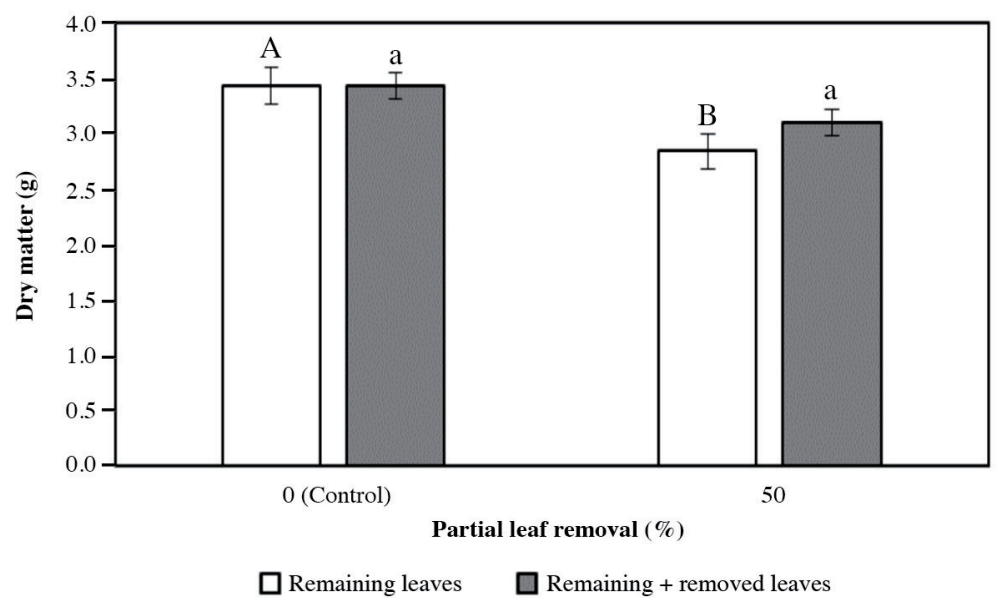

The ANOVA was performed separately for the variables represented by the white and gray bars. Tukey's HSD test results are shown in uppercase or lowercase letters, indicating that the statistical analyses were performed separately. Error bars indicate standard error.

Figure 3. Leaf area per plant at harvest (white bars) and sum of leaf area at harvest plus leaf area of removed leaves (gray bars) in lettuce plants (Lactuca sativa) subjected to partial leaf removal $(n=50)$.

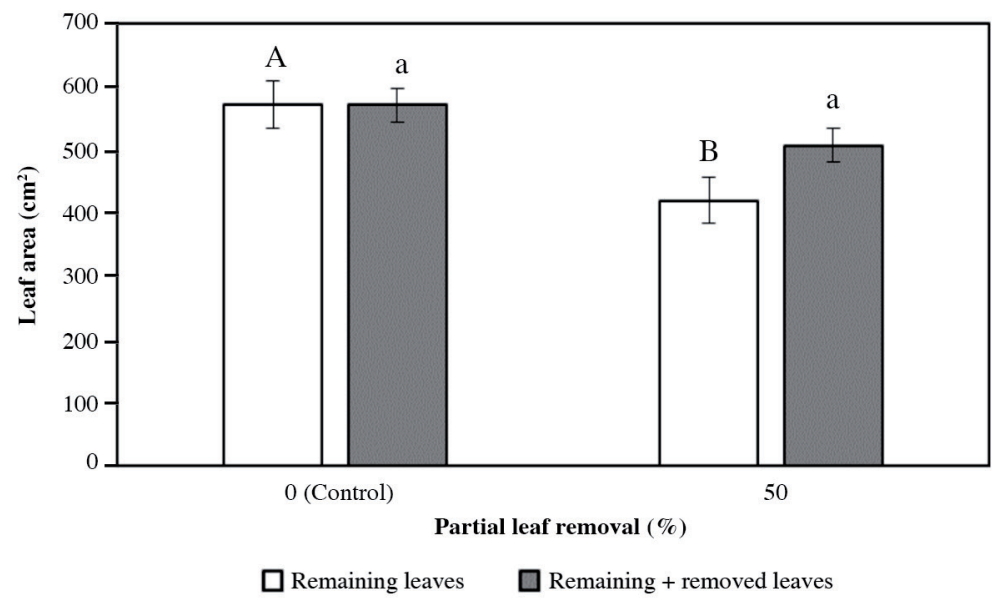

The ANOVA was performed separately for the variables represented by the white and gray bars. Tukey's HSD test results are shown in uppercase or lowercase letters, indicating that the statistical analyses were performed separately. Error bars indicate standard error.

Dry weight of all the leaves at harvest (66 d after transplanting) decreased for the partially defoliated plants compared with the control plants despite the nonsignificant difference in the biomass percentage related to the leaves (Table 1) or leaf weight ratio. This is because leaf dry weight was an absolute value, while DM partitioning and leaf weight ratio were relative values between the dry weight in the different plant tissues. These values were modified according to the amount of dry mass allocated to each of the examined tissues (leaves, stems, and roots). Although mean values were not significantly different for the specific leaf area, this variable showed a lower mean value in partially defoliated plants $\left(24.5 \mathrm{~mm}^{2} \mathrm{mg}^{-1}\right)$ when compared with the control plants $\left(27.3 \mathrm{~mm}^{2} \mathrm{mg}^{-1}\right)$ (Table 1). This indicates that leaves of partially defoliated plants were slightly heavier per unit area, but $26.6 \%$ lower compared with the control plants. 
Figure 4. Leaf dry weight at harvest (white bars) and sum of leaf dry weight at harvest plus dry weight of removed leaves (gray bars) in lettuce plants (Lactuca sativa) subjected to partial leaf removal $(\mathbf{n}=\mathbf{5 0})$.

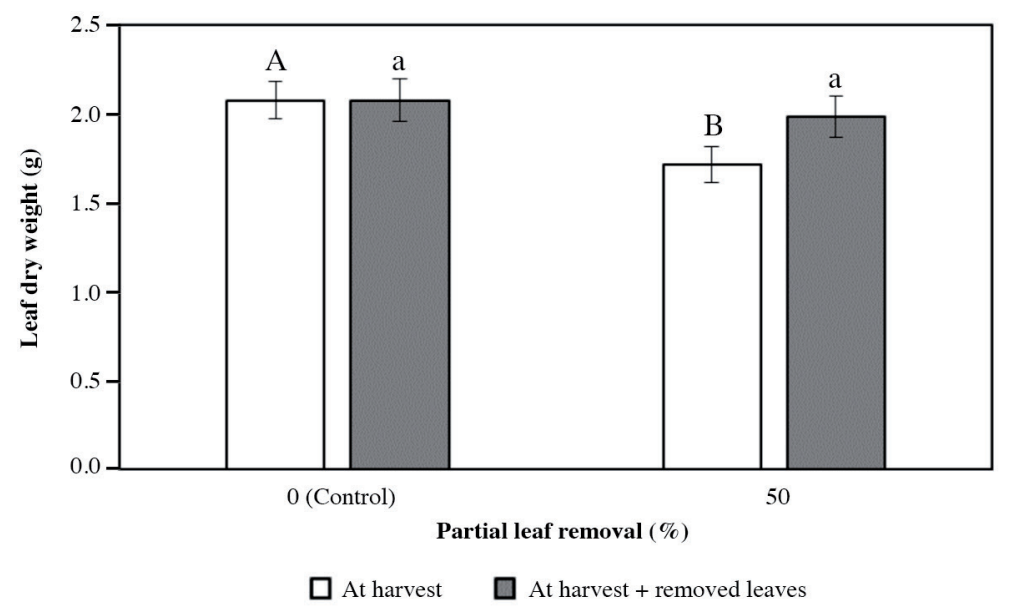

The ANOVA was performed separately for the variables represented by the white and gray bars. Tukey's HSD test results are shown in uppercase or lowercase letters, indicating that the statistical analyses were performed separately. Error bars indicate standard error.

\section{DISCUSSION}

Unlike the results found in the current study for allometric coefficients, Casierra-Posada et al. (2017) found modifications in the DM distribution pattern in the different plant tissues of Vicia faba (broad beans) with 50\% defoliation. The amount of accumulated biomass decreased in the roots but increased in the leaves when compared with the control plants. In the present study, partial defoliation did not significantly affect dry mass distribution in the different plant tissues.

Although no difference was found between treatments for the specific leaf area in the present study, Casierra-Posada et al. (2017) indicated that the value of this variable decreased by $25 \%$ in defoliated $V$.faba plants when compared with a control group. The leaf weight ratio values recorded in the present study showed nonsignificant difference between the treatment means; however, the value of this variable increased $14.6 \%$ in $V$. faba plants subjected to $50 \%$ defoliation compared with control plants (Casierra-Posada et al., 2017).

Casierra-Posada et al. (2017) mentioned that when leaf area was partially reduced, stem growth increased, thus affecting root growth. However, the root to shoot ratio after defoliation was restored to a value similar to that of plants before partial leaf removal. This aspect was reflected in the results of the present study because the root to shoot ratio and leaf area ratio were not significantly different. This implies that there is compensatory leaf growth of partially defoliated plants. The root to shoot ratio and leaf area ratio were similar between control and partially defoliated plants (Table 1). Partial defoliation did not affect harvestable DM, which is considered as relevant for this plant, because the harvestable portion of this vegetable is the shoot. Based on the variables applied to lettuce plants in which nonsignificant difference was found between treatments, it can be inferred that $L$. sativa shows tolerance to partial defoliation by leaf area removal. In addition, the tolerance of this vegetable is comparatively greater than in V. faba plants (Casierra-Posada et al., 2017).

Boogaard et al. (2001) reported a drastic decrease in the leaf area ratio after defoliation; however, the value of this variable increased over time in partially defoliated plants in which half of the leaves were removed and reached values of intact plants. The results of the present study show a trend to restore the balance in the growth variable values of the partially defoliated plants (Table 1). Regarding the CCI in the present study, Joudi et al. (2006) found that partial defoliation in wheat increased both the chlorophyll content and net photosynthetic rate of the remaining leaves. The rate of increase depended on the cultivars. This result was also reported by Peña-Olmos and Casierra-Posada (2013), who pointed out that removing $50 \%$ of the leaf area in $V$. vinifera plants increased CCI by $9.1 \%$ when compared with the control plants. 
Our results concur with findings by Quentin et al. (2010), who reported that artificial defoliation in Eucalyptus globulus seedlings markedly increased the chlorophyll concentration in the remaining leaves. Both defoliation by insects and artificial defoliation of these seedlings increased the photosynthetic capacity $\left(\mathrm{A}_{\max }\right)$, which they attributed to higher leaf chlorophyll content. This increased chlorophyll content was related to an increased content of enzymes involved in photosynthesis. Despite the increased photosynthetic rate and chlorophyll content, the total amount of biomass in the plants under the two defoliation methods (artificial and insects) decreased, as shown in the current study. Boogaard et al. (2001) mentioned that the net assimilation rate per unit leaf area in partially defoliated cauliflower (Brassica oleracea var. botrytis) plants was higher during the whole growth cycle in plants subjected to partial defoliation when compared with control plants. However, a lower amount of non-structural carbohydrates was recorded in partially defoliated plants due to their reallocation in the tissues to maintain regrowth caused by partial defoliation. In the present study, the results of the variables related to the growth of plants subjected to partial defoliation could be caused by higher capture of sunlight by the chlorophyll. The increased concentration of the variables was due to the partially removed leaf area. More photosynthates were produced that would otherwise be used to create new leaves to compensate the removed leaf area.

As for decreased RGR and AGR caused by defoliation, a similar situation occurred for strawberry (Fragaria spp.) plants in which $38 \%$ and $67 \%$ of the leaf area was removed and AGR decreased by $35.5 \%$ and $61.9 \%$, while RGR decreased by $17.7 \%$ and $38.5 \%$, respectively, compared with control plants (Casierra-Posada et al., 2012). Boogaard et al. (2001) indicated that RGR decreased over time in B. oleracea var. botrytis plants subjected to approximately 65\% partial defoliation $v s$. intact plants. When comparing RGR values in partially defoliated and intact plants, the partially defoliated plants in some cases had double the recorded values for intact plants. These authors justified the results on the grounds that increased RGR in partially defoliated plants was caused by a higher net assimilation rate due to a higher photosynthetic rate. However, these same authors state the most probable explanation for this result is that a high photosynthetic rate was achieved by partial defoliation. This rate was probably due to the greater capture of sunlight by the remaining leaves and because partial defoliation decreased the internal shading of the plant.

Khan et al. (2002) mentioned that plants produce phenols and hydrogen peroxide as a result of defoliation, both of which act as a protective mechanism. The produced phenols also induce the synthesis of indoleacetic acid (IAA) oxidase, which promotes IAA catabolism. Lv et al. (2019) described in detail how auxins are among the most important plant hormones for their mediating function in the endogenous growth-inducing signals and exogenous environmental signals. Given the relationship between IAA and plant growth, the present study demonstrated that reduced growth in partially defoliated lettuce plants can be justified by decreased IAA activity. An increase in the number of leaves was observed after partial defoliation in the present study. Khan et al. (2002) reported that partial defoliation of brown mustard (Brassica juncea) caused the emergence of new leaves and showed that the highest value in the number of leaves occurred when the bottom leaves were removed. These authors mentioned that these new smaller leaves combined with the existing leaves could not compensate for the original total leaf area, and leaf area was higher in plants in which only the upper leaves were partially removed. The larger leaves also exhibited a decreased net photosynthetic rate because they were above the point of light saturation, which decreased plant biomass. Our results for L. sativa plants affected by defoliation showed a great advantage regarding leaf area renewal by the emergence of new leaves. The leaves are the harvestable portion of this vegetable attacked by slugs (Córdoba and León, 2010): it is beneficial that the plant can partially renew the removed leaf area. In some cases, the number of leaves was higher than that of the control plants. The partial defoliation of the leaf area promotes the emergence of new leaves aimed at reestablishing the balance between the tissues that make up the plant. Table 1 shows that plant growth and DM partitioning are not drastically affected by partial defoliation. Regarding the decrease in total dry mass per plant induced by partial defoliation, Quentin et al. (2010) found that E. globulus plants under artificial and insect defoliation significantly decreased total biomass by $28.3 \%$ and $16 \%$, respectively, compared with the control group. Additionally, Casierra-Posada et al. (2012) mentioned decreased dry weight per plant because of defoliation in strawberry plants. Plants in which $38 \%$ and $67 \%$ of the leaf area was removed, the value of this variable decreased by $34.1 \%$ and $58.6 \%$, respectively, compared with the control plants. In partially defoliated B. oleracea var. botrytis, Boogaard et al. (2001) showed that the dry weight of plants subjected to approximately $65 \%$ defoliation decreased by $10 \%$ to $25 \%$ of the dry weight of intact plants. These percentages were based on different treatments related to different cultivars and leaf age. Decreased total dry weight of the plants subjected to partial defoliation could be expected, given the removal of half the leaf area of these plants. The leaves represented $60.5 \%$ of the total dry weight of the control plants (Table 1). However, results demonstrated that partial defoliation stimulates new leaf growth as a compensatory mechanism (Figure 1). 
Partial defoliation assays should have reduced the plants to approximately $50 \%$ of the leaf area compared with the control plants because each new leaf had half of its area removed. However, this occurred before the leaf had finished its growth and reached adulthood. Removing half of each young leaf could stimulate additional growth in the portion of each remaining leaf. Plants subjected to partial defoliation showed an $88.8 \%$ leaf area compared with the control. It can therefore be assumed that partially defoliated plants managed to compensate for approximately $38.8 \%$ of the leaf area in response to the partial removal of the leaf area. This same effect was observed by Casierra-Posada et al. (2017), who encountered that $V$. faba plants subjected to partial defoliation decreased total leaf area at the end of the assay to $38.8 \%$ in plants with 50\% partial defoliation compared with the control plants without defoliation. Casierra-Posada et al. (2017) expected that the final leaf area would be consistent with the intensity of partial defoliation in implemented treatments. However, plants in which half of each leaf was removed showed decreased leaf area below this value (38.8\% instead of 50\%) because partially defoliated plants produced a larger number of leaves than the control plants. Thus, it can be concluded that new leaves act as a compensatory mechanism, which was observed in the present study (Figure 1).

In accordance with decreased leaf dry weight caused by partial defoliation, Casierra-Posada et al. (2012) showed that when strawberry plants were exposed to a $38 \%$ to $67 \%$ decrease in leaf area compared with the control plants, the proportion of DM allocated to the leaves and petioles decreased compared with DM allocated to the other plant tissues.

Although differences have already been mentioned for total leaf dry weight, Figure 4 demonstrates that despite a 50\% loss of leaf area, the difference between leaf dry weight at harvest and the sum of the dry weight of the removed leaves was only $11 \%$. This indicates that the plants subjected to partial defoliation showed a high degree of leaf area renewal. This renewal could be achieved through greater capture of light from increased CCI and higher leaf production as a response to partial defoliation. This feature is considered a benefit provided that plants in an open field or greenhouse are not immune from being affected by herbivores and phytopathogens. Likewise, plants are not protected against a partial loss of leaf area due to abiotic stress.

Quentin et al. (2011) found that E. globulus with 45\% removed leaf area showed decreased total leaf weight. Plants subjected to leaf removal had a $10.1 \mathrm{~kg}$ tree $\mathrm{e}^{-1}$ dry leaf weight compared with $12.2 \mathrm{~kg}$ tree $\mathrm{e}^{-1}$ for the control. The authors mention that E. globulus plants are able to perform compensatory renewal if leaf area is removed. In addition, the shoots that emerged after defoliation had leaves with a higher specific leaf area value, providing them with an advantage in the efficient use of resources for the capture of light. Qiu et al. (2016) reported decreased leaf dry weight in red raspberry (Rubus idaeus) plants. The reduction of this variable only occurred when the floricanes were partially defoliated. This was because partial leaf removal in the primocanes did not produce significant results between partially defoliated plants and the control. In addition, red raspberry plants can maintain an up-regulation of the leaf specific hydraulic/photosynthetic capacity throughout the fruiting season, despite a reduced leaf area index caused by decreased photosynthate supply due to partial defoliation. Another important aspect is that leaf specific hydraulic conductance increases when there is partial leaf area loss in a plant. In this case, stomatal conductance of the remaining leaves generally increases. All of these factors contribute to the ability of $L$. sativa plants to compensate for leaf area loss due to partial defoliation. This renewal helps restore much of the lost leaf area to achieve a balance of the growth variables and fulfil the plant lifecycle without any major difficulties.

\section{CONCLUSIONS}

Results showed that there was nonsignificant difference in dry matter partitioning between control plants and partially defoliated plants; this is an indicator of the regenerative ability of plants after partial defoliation. Other plant growth variables showed nonsignificant differences between treatments. However, it is important to note that the lack of a significant difference in harvestable dry matter should be considered as positive. The leaves, which are an edible portion of these plants, are not altered in spite of partial defoliation. This ability to renew lost growth is achieved through an increase in the chlorophyll content index and emergence of new leaves. These factors contribute to the better capture of light and increase photosynthate production so that growth is not severely affected by partial defoliation. 


\section{ACKNOWLEDGEMENTS}

This study was funded by the Faculty of Agricultural Sciences at the Universidad Pedagógica y Tecnológica de Colombia (UPTC) and with the help of the Plant Ecophysiology Research Group.

\section{REFERENCES}

Boogaard, R.V.D., Grevsen, K., and Thorup-Kristensen, K. 2001. Effects of defoliation on growth of cauliflower. Scientia Horticulturae 91:1-16. doi:10.1016/S0304-4238(01)00234-5.

Casierra-Posada, F., Cutler, J., and Reyes-Copasachoa, D. 2017. Tolerance of faba bean plants (Vicia faba) to partial defoliation. Gesunde Pflanzen 69:165-170. doi:10.1007/s10343-017-0401-0.

Casierra-Posada, F., Torres, I.D., and Blanke, M.M. 2013. Fruit quality and yield in partially defoliated strawberry plants in the tropical highlands. Gesunde Pflanzen 65:107-112. doi:10.1007/s10343-013-0303-8.

Casierra-Posada, F., Torres, I.D., and Riascos-Ortíz, D.H. 2012. Growth in partially defoliated strawberry plants cultivated in the tropical highlands. Revista U.D.C.A Actualidad \& Divulgación Científica 15(2):349-355.

Córdoba, C.A., y León, T. 2010. Efecto del manejo agroecológico y convencional sobre la fluctuación de babosa en cultivos de lechuga en Tenjo, Cundinamarca (Colombia). Acta Biológica Colombiana 15:115-128.

Hunt, R. 1990. Basic growth analysis. Plant growth analysis for beginners. Unwin Hyman Ltd., London, UK. doi:10.1007/978-94-010-9117-6.

Joudi, M., Ahmadi, A., Poustini, K., and Sharifzadeh, F. 2006. Effect of leaf elimination on the effectiveness of flag leaf photosynthesis and seed growth in bread wheat. Iranian Journal of Agriculture Science 2:203-211.

Khan, N.A., Khan, M., Ansari, H.R., and Samiullah. 2002. Auxin and defoliation effects on photosynthesis and ethylene evolution in mustard. Scientia Horticulturae 96:43-51. doi:10.1016/S0304-4238(02)00094-8.

Lv, B., Yan, Z., Tian, H., Zhang, X., and Ding, Z. 2019. Local auxin biosynthesis mediates plant growth and development. Trends in Plant Science 24:6-9. doi:10.1016/j.tplants.2018.10.014.

Paixao, C., Krause, C., Morin, H., and Achim, A. 2019. Wood quality of black spruce and balsam fir trees defoliated by spruce budworm: A case study in the boreal forest of Quebec, Canada. Forest Ecology and Management 437:201-210. doi:10.1016/j.foreco.2019.01.032.

Peña-Olmos, J.E., and Casierra-Posada, F. 2013. Chlorophyll fluorescence in partially defoliated grape plants (Vitis vinifera L. cv. Chardonnay). Revista Facultad Nacional de Agronomía Medellín 66:6881-6889.

Peña-Olmos, J.E., and Casierra-Posada, F. 2015. Fruit quality and production of Vitis vinifera L. Chardonnay affected by partial defoliation in tropical highlands. Revista Facultad Nacional de Agronomía Medellín 68:7581-7588.

Peña-Olmos, J.E., Casierra-Posada, F., and Herzberg, M. 2013. Effect of partial grapevine defoliation (Vitis vinifera) on wine quality. Revista Facultad Nacional de Agronomía Medellín 66:6891-6898.

Quentin, A.G., Beadle, C.L., O'Grady, A.P., and Pinkard, E.A. 2011. Effects of partial defoliation on closed canopy Eucalyptus globulus Labilladière: Growth, biomass allocation and carbohydrates. Forest Ecology and Management 261:695-702. doi:10.1016/j.foreco.2010.11.028.

Quentin, A.G., Pinkard, E.A., Beadle, C.L., Wardlaw, T.J., O’Grady, A.P., Paterson, S., et al. 2010. Do artificial and natural defoliation have similar effects on physiology of Eucalyptus globulus Labill. seedlings? Annals of Forest Science 67:203. doi:10.1051/forest/2009096.

Qiu,C.,Ethier, G., Pepin, S., Xu, Q., Gosselin,A., and Desjardins, Y.2016. Hydraulic and photosynthetic compensation versus fruit yield of red raspberry following partial leaf defoliation. Scientia Horticulturae 213:66-75. doi:10.1016/j.scienta.2016.10.007.

Santacruz, A., Toro, M., and Salazar, C. 2011. Slugs control methods (Deroceras sp. Müller) in lettuce and broccoli crops. Agronomía Colombiana 29:241-247.

Santos, R.O., Neto-Soares, R., Pimentel, M., Abreu, J., Lima, R., and Silva, B. 2018. Modeling the leaf area of Ormosia paraensis Ducke by statistical models and artificial neural networks. Chilean Journal of Agricultural Research 78:511-520. doi:10.4067/S0718-58392018000400511. 